\title{
El desfile de lo femenino. Las mujeres de la Sección Femenina y las celebraciones franquistas en Granada (1937-1951)
}

\author{
The Feminine Parade. 'Sección Femenina' Women and the \\ Francoist Celebrations in Granada (1937-1951)
}

\author{
Francisco Jiménez Aguilar \\ Universidad de Granada \\ fjja@correo.ugr.es \\ ORCID: 0000-0002-6194-5089
}

Recibido: 08-04-2018

Aceptado: 23-07-2018

Cómo citar este artículo / Citation: JIMÉNEZ AGUILAR, Francisco. El desfile de lo femenino. Las mujeres de la Sección Femenina y las celebraciones franquistas en Granada (1937-1951). Pasado y Memoria. Revista de Historia Contemporánea, 17, pp. 389-412. https://doi.org/10.14198/PASADO2018.17.14

\section{Resumen}

Una de las cuestiones más debatidas sobre la Sección Femenina de Falange durante el franquismo han sido los límites de su agencia y cómo esta fue representada en la esfera pública. En este artículo se plantea cuál era el papel de las mujeres falangistas dentro del calendario y las celebraciones franquistas: sus festividades, su lugar y función en los rituales, su voz y presencia en los discursos y los símbolos. Con ello se observará cómo la organización femenina fascista era partícipe y estaba simbolizada en el imaginario colectivo del franquismo al tiempo que se legitimaba la posición subalterna de las mujeres.

Palabras clave: Calendario. Celebraciones. Esfera Pública. Franquismo. Sección Femenina de Falange.

\section{Abstract}

One of the most controversial issues about Falange's 'Sección Femenina' in Franco's times has been related to the limits of its agency and to how this was represented in 
public sphere. This work examines the role of Falangist women in Francoist calendar and festivities: their celebrations, their position and role in rituals, their voice and presence in discourses and symbols. As a result, we observe how the female fascist organization was part of and was represented within the social imaginary of Francoism while women's inferior position was legitimized.

Keywords: Calendar. Celebrations. Public Sphere. Francoism. 'Sección Femenina' of Falange.

Una de las problemáticas más debatidas en torno a las mujeres de la Sección Femenina de Falange ha sido los límites de su agencia. ${ }^{1}$ Con el propósito de examinar cuál fue el marco político que determinó su acción y qué posición social ocuparon las mujeres falangistas durante el franquismo pueden continuar resultándonos útiles conceptos como los de "esfera privada" y "esfera pública", que formuló el filósofo Jürgen Habermas (1989) y que han desarrollado con posterioridad muchas historiadoras feministas, a fin de comprender los planos en los que se acotaron y disputaron las relaciones de poder a lo largo de la historia contemporánea. Incluso, para analizar los regímenes fascistas del periodo de entreguerras, caracterizados hasta hace poco como carentes de estas esferas, como ha propuesto recientemente Claudio Hernández (2016a: 188-193).

Siendo conscientes del carácter abstracto y versátil de estas esferas, pues determina la concepción de los escenarios en los que se representan y establecen los discursos que articulan las relaciones políticas, económicas y culturales (Smitley, 2009: 40-59), la "esfera pública" (Öffentlichkeit) abarcaría todo el espacio político colectivo -el cual no se limita únicamente al espacio gubernamental-administrativo- donde interactúan las diferentes opiniones de los sujetos políticos. Mientras que, por otro lado, la "esfera privada" comprendería el espacio donde los sujetos interactúan con ellos mismos y con las instituciones que los rodean como la familia. De este modo el poder incide en mayor medida sobre uno mismo y no está directa o plenamente mediado por el Estado o el resto de la sociedad (Habermas, 1989). De tal modo que el reconocimiento de ambas esferas nos permite señalar los espacios en los que a través de la producción de discursos se organiza el conjunto de la sociedad, especialmente bajo los regímenes democráticos, aunque no solo en ellos.

A pesar de los aspectos difusos y los puntos ciegos que pueden presentar conceptos como los de esfera pública y privada para el estudio de la agencia

\footnotetext{
${ }^{1}$ Esta cuestión ha sido continuamente objeto de reflexión en las investigaciones sobre la Sección Femenina, sin embargo, algunos de los ensayos que han abordado esta problemática más directamente son: Gallego Méndez (1983); Sánchez López (1990); Barrachina (1991); Molinero (1998); Enders (1999); Richmond (2004); Cenarro (2006, 2011 y 2017); Prada Rodríguez (2006); Ofer (2009); Tavera García (2011); Morant (2012).
} 
de las mujeres durante el fascismo (Davis, 1996; Eley, 2002), autoras como Nancy Fraser (2015) han apuntado la posibilidad de reelaborarlos. Por una parte, aunque se ha puesto de manifiesto la capacidad de los regímenes fascistas de difuminar ambas esferas para penetrar en la esfera privada y controlar y limitar radicalmente la opinión en la esfera pública, no puede negarse tampoco la capacidad que tuvo la gente en su vida cotidiana tanto de sostener estos marcos políticos como de subvertir algunos de sus aspectos o de terminar ayudando a acabar con ellos (Corner, 2013). Seguir observando aquellos espacios desde los que se disputaron las relaciones de poder, ya sea para sostenerlas o transformarlas, es fundamental si queremos comprender la incidencia del fascismo en las vidas de las mujeres y en su capacidad de actuar. Por otra parte, ya se ha señalado cómo la definición habermasiana de la esfera pública no permite comprender las relaciones de poder que median sobre las mujeres, especialmente en términos culturales, así como los distintos medios que estas disponen en cada contexto histórico para intervenir en ella (Fraser, 1990; 2015: 39-74). Sin embargo, si nos basamos en un enfoque preformativo de estas (Butler, 2015), donde se ponga en un primer plano cómo interactúan las prácticas discursivas, podremos ver cómo las mujeres han intervenido de múltiples formas en la configuración de los discursos hegemónicos y en su subversión. Por esta razón, seguir acercándonos a estas esferas puede servirnos para examinar los cambios que se han dado a lo largo de la historia en la agencia de las mujeres más allá de los muros del parlamento o el hogar.

El estudio de la agencia (agency), como capacidad de actuar dentro de los marcos políticos en un contexto histórico concreto, es desde hace tiempo uno de los principales intereses de la historia de las mujeres y de género. Dentro de nuestra definición de esfera pública, al entender lo político, lo económico y lo cultural como discursos fundamentales en continua disputa y negociación por los sujetos políticos, podemos entender la agencia como una cualidad preformativa (Butler, 2010), esto es, como capacidad de repetición o cambio de determinados aspectos por medio de diferentes prácticas discursivas. Por lo tanto, examinar la multiplicidad de acciones que constituyen o deconstruyen las lógicas y normatividades que rigen nuestra cotidianeidad es imprescindible para el análisis de las formas de subjetivización de las mujeres, las feminidades o los marcos de dominación patriarcal. Y aunque el estudio de la agencia ha sido orientado principalmente al análisis de cómo las mujeres transforman estos marcos, especialmente los de sexo y género, también nos puede servir para conocer cómo las mujeres han participado individual (Lorey, 2017) y colectivamente (Butler, 2017a) en los propios procesos de constitución y estabilización de los marcos de dominación (Mahmood, 2001). 
Los cambios legislativos y prácticos que se dieron en los derechos de las mujeres durante la Segunda República fueron desplazados hacia posiciones antifeministas con la emergencia del franquismo (Di Febo, 1979; Ruiz Franco, 2007; Moraga García, 2008). Estos cambios tan profundos continúan despertando el interés historiográfico por sus características y los medios que permitieron el proceso de mutación y pérdida generalizada de la agencia femenina. Del mismo modo, resulta muy importante problematizar cuál fue el papel que desempeñaron mujeres como las pertenecientes a la Sección Femenina de Falange, aquellas que podríamos considerar entre las españolas con mayor agencia en la esfera pública durante esta época, por su capacidad de enunciación y por las contradicciones que generaban. Gran parte de los discursos hegemónicos del franquismo legitimaron permanentemente la "naturaleza" maternal y el "deber" de atender el hogar como algo intrínsecamente femenino, por lo que las mujeres debían permanecer en la esfera privada. En cambio, las mujeres de la Sección Femenina planteaban una excepción a la regla. Al ser las "mujeres azules" disponían de una posición anómala que les confería la posibilidad de traspasar del ámbito privado a la esfera pública, no solo con la potestad de ordenar, educar y formar a las mujeres, sino participando también junto a los hombres en los diferentes ámbitos asistenciales, laborales, sociales y culturales, aunque, qué dudada cabe, que en desigualdad (Rodríguez López, 2010).

Si queremos conocer la agencia de estas mujeres y cómo ellas mismas participaron activamente en la producción, estabilización y cambio de los marcos que determinaban las relaciones de género debemos acercarnos a estos elementos culturales. Observando el peso que poseyó la producción cultural del franquismo como ha demostrado la historiografía en la última década, el análisis de elementos como las celebraciones y festividades desde un enfoque de género puede ayudarnos a comprender mejor los cambios de este periodo. En esta dirección, el objetivo de este ensayo será analizar la capacidad de agencia de las mujeres de la Sección Femenina en la esfera pública a través de su participación en las celebraciones franquistas.

Para ello, previamente, deben mostrarse algunas de las premisas historiográficas desde las que se parten, a la vez que exponer el marco espacio-temporal y las fuentes utilizadas. En primer lugar, el franquismo provocó un profundo "arrinconamiento" de las mujeres en la esfera pública. La consolidación del régimen, sus culturas políticas y las políticas de género que estas propugnaban supuso que muchos de los cambios que se habían producido previamente en materia jurídica y práctica para alcanzar una mayor igualdad entre hombres y mujeres se redujeran radicalmente o suprimieran para que las mujeres hicieran su vida dentro del hogar y lo que este suponía (Morcillo Gómez, 
2015: 68). Consecuentemente, se refeminizó la esfera privada mediante todo tipo de dispositivos legislativos, médico-demográficos e ideológicos para limitar gran parte de la agencia de las mujeres (Cayuela Sánchez, 2014: 172-185).

En segundo lugar, y pese a lo expuesto, durante la dictadura continuó existiendo una representación pública de las mujeres en el ordenamiento político y simbólico, como fue el caso de las celebraciones y las festividades, así como en otros elementos culturales propios de esta (Lavail, 2008). La historiografía que ha tratado este tema desde la historia política, la historia de las mujeres o la historia cultural muchas veces ha ignorado o no ha prestado la suficiente atención al carácter también generizado de estas (Ortega López, 2010: 209-211), pero no podemos ignorar que cuantitativa y cualitativamente se incorporó a una parte de las mujeres a este tipo de manifestaciones políticas para adherir, socializar y trazar muchas de las identidades de género. En este sentido, la representación política femenina del régimen franquista, encarnada principalmente por las mujeres de la Sección Femenina y por las de otras organizaciones como Acción Católica, siguió teniendo su lugar en los espacios públicos (Blasco Herranz, 2005: 64-65).

En tercer lugar, esta representatividad política respondería a los principales rasgos de la Sección Femenina que, como la mayoría de las historiadoras han señalado, ha de ser considerada como "antifeminista" (Sánchez López, 1990; Enders, 1998; Ortega López, 2008). No obstante, algunos de los trabajos que se han preocupado por llevar a cabo un análisis de género de la Sección Femenina han señalado las amplias contradicciones que existían dentro de esta (Cenarro, 2017), como por ejemplo, el hecho de que su antifeminismo no fuera radicalmente regresivo en temas como la educación o el trabajo de las mujeres, la "excepcionalidad" de algunos de los modelos femeninos que esta propugnaba o la percepción de las limitaciones de su agencia y de su papel como sostenedoras de la exclusión femenina (Barrachina, 1991; Cenarro, 2006; Ofer, 2009). Buscar las acciones performativas de las mujeres de la Sección Femenina puede ayudarnos a alcanzar una visión más compleja de las transformaciones que se dieron en las relaciones de género, cómo se difundieron las feminidades que estas auspiciaban y cuáles fueron las diversas actitudes que mostraron las españolas frente a las políticas de género del franquismo.

Por medio del estudio de algunas celebraciones franquistas donde la Sección Femenina participó, como el Día de Santa Teresa, el 20 de noviembre o la festividad de San Isidro, vamos a analizar su agencia y algunos caracteres de las feminidades hegemónicas que se reprodujeron durante estas. Para ello nos hemos basado en un estudio "desde lo local" que partiendo de la Granada del primer franquismo nos permita continuar arrojando luz sobre algunos aspectos de la Sección Femenina y la labor que desempeñó, como en muchas otras 
provincias, en la construcción de las bases de la dictadura no solo desde el plano material, sino también cultural y simbólico (véase Morales Villena, 2010; Jiménez Aguilar, 2017; 2018). Asimismo, al estudiar estas festividades a través de fuentes archivísticas y hemerográficas, hemos podido acercarnos a las culturas políticas del franquismo y su desarrollo discursivo en este momento.

\section{El calendario franquista}

Si bien para el "Nuevo Estado" la construcción simbólica del tiempo y los rituales fue fundamental desde que comenzó la Guerra Civil (Di Febo, 2012), una vez concluyó esta fue un elemento indispensable para su legitimación y la de aquellos que lo apoyaban. A partir de la organización de los símbolos nacionales, las conmemoraciones y la puesta en escena de distintos rituales se consiguió reproducir eficazmente lo que se ha venido a denominar la "Cultura de la Victoria".

La "Cultura de la Victoria" emergió durante la guerra de la disputa por la hegemonía que se produjo dentro y fuera de cada uno de los frentes y retaguardias, lo cual permitió fraguar una nueva cultura franquista de los "vencedores". Con ella, el régimen franquista y sus apoyos sociales lograron erigir una base cultural nacional con la que, a través de mitos, ritos y símbolos, a la par que de identidades, prácticas y modelos sociales, sostener el consenso y el consentimiento suficientes para mantenerse en el poder (Saz Campos, 2004: 174-177; Del Arco Blanco, 2009; Hernández Burgos, 2011; 2016b). Todos estos elementos se fueron configurando a partir de las tensiones culturales entre la dictadura y el gobierno republicano así como la pugna entre las culturas políticas nacionalsindicalista y nacionalcatólica (Saz Campos, 2010), los discursos modernos de la revolución y la tradición, las nuevas formas de articulación entre el Estado y el pueblo, la gestión de los apoyos sociales, las zonas grises y las disidencias, o la inclusión selectiva de la herencia nacional y las influencias liberales, fascistas y católicas que llegaban del exterior en aquel momento. Luego elementos como las celebraciones y las festividades sirvieron dentro de la esfera pública para producir o reforzar las identidades y subjetividades que sostendrían el franquismo. ${ }^{2}$

El nuevo "Calendario de Fiestas Oficiales"3 que fue establecido durante los primeros años del régimen reguló cómo debían representarse diferentes ideas,

\footnotetext{
${ }^{2}$ Sobre la "Cultura de la Victoria" véanse los trabajos de del Arco Blanco (2009: 251260); Hernández Burgos (2011; 2016b); Cobo Romero, del Arco Blanco y Ortega López (2011: 46-52).

${ }^{3}$ Boletín Oficial del Estado (BOE): "ORDEN de 9 de marzo de 1940 disponiendo el Calendario de Fiestas Oficiales", 73, 9-3-1940, 1767.
} 
mitos o valores nacionales y religiosos (Cenarro, 2003; Box, 2007). Había un día para celebrar la figura de Francisco Franco (1 de octubre) y para conmemorar a José Antonio Primo de Rivera (20 de noviembre). Otras fechas se crearon para mitificar el triunfo del franquismo sobre la República, como el "Día de la Victoria" (1 de abril), o se estableció el "Día de la Unificación" (19 de abril) para representar la supremacía política de Falange frente a las demás organizaciones políticas que había. También, se celebraron numerosos símbolos católicos como la Inmaculada Concepción (8 de diciembre) o el Apóstol Santiago (25 de julio) y se resignificaron otras festividades como el "Día de la Raza" (12 de octubre), para simbolizar el hermanamiento paternalista de España con sus excolonias latinoamericanas. En definitiva, en la España franquista, como ocurrió en otros regímenes fascistas (Gentile, 1990; Mosse, 2005: 101-165), el calendario fue un arma más para alcanzar sus metas políticas (Box, 2010: 280).

En el ámbito local, muchas de las fiestas fueron vistiéndose de los símbolos y rituales propios de la cultura franquista. Durante los primeros años de la dictadura estas fueron acomodadas a las necesidades de legitimación de las nuevas corporaciones y gobiernos municipales, así como a las de la propia dictadura de acuerdo con las especificidades regionales de cada lugar (Núñez Seixas, 2006). Para el caso de una ciudad como Granada, donde existían festividades de carácter religioso, nacionalista o propiamente local, como el "Día de la Toma" (2 de enero), la Semana Santa, la festividad de la Virgen de las Angustias, el "Día de la Cruz" (3 de mayo) o las fiestas del Corpus Christi, estas fueron poco a poco tiñéndose del azul falangista e iluminándose con el resplandor de los cirios nacionalcatólicos (Hernández Burgos, 2011: 263-319). Sin embargo, pese a que todas ellas servirían de arena para el enfrentamiento entre las distintas culturas políticas franquistas, desde sus diferencias todas confluirían en un mismo fin: normalizar el franquismo (Hernández Burgos, 2011: 263-319; Rina Simón, 2015; Ipiña Bidaurrazaga, 2014; Antuna Gancedo, 2016).

Simultáneamente, muchas de las festividades del periodo republicano fueron eliminadas. Los carnavales se prohibieron durante un tiempo con la excusa de las carencias que se vivían durante la guerra, aunque no se pasara por alto el carácter disruptivo y crítico que poseían. ${ }^{4}$ El "Día del Trabajo" fue tachado para más tarde ser suplantado por la festividad del "Día del Pueblo Trabajador" (19 de mayo), que suprimía cualquier connotación contestataria que

${ }^{4}$ De ello los intentos de Ramón Serrano Suñer de mantener su prohibición: BOE: "ORDEN de 12 de enero de 1940 resolviendo mantener la prohibición absoluta de la Celebración de fiestas de Carnaval”, 13, 12-2-1940, 277. 
esta pudiese tener en favor de la lógica económica y sindical franquista. Asimismo, todas aquellas festividades que tenían algún vínculo con la Segunda República, como el 11 de febrero o el 14 de abril, fueron fulminadas del almanaque.

A lo largo de todas estas celebraciones, en la organización de los rituales, los símbolos y los discursos las mujeres contaban como un elemento social necesario y, por consiguiente, como sujetos a representar. El franquismo era en todo momento consciente de ellas, lo cual no quiere decir que las mujeres tuvieran un lugar privilegiado en la organización litúrgica, en la ordenación espacial de los participantes o en la intención y reproducción de los discursos normativos. Pero sí que ocupaban simbólicamente el lugar en el que estas se hallaban dentro del marco político vigente: un lugar subalterno. Un espacio que se podía observar muy bien en las celebraciones donde las mujeres de la Sección Femenina participaban habitualmente.

\section{Las mujeres de la Sección Femenina en las celebraciones franquistas}

Las mujeres de la Sección Femenina, por lo general, carecían de presencia dentro de los discursos y las proclamas, ocupaban una posición rezagada en la ordenación humana del espacio ritual y, habitualmente, dentro del público cubrían de manera forzosa los numerosos sitios que estaban vacíos. En muchas ocasiones, bajo diferentes incentivos o formas de castigo eran coaccionadas a ocupar los huecos que había en las siempre exageradas por la propaganda manifestaciones y celebraciones franquistas, las cuales no podían compararse en número con las de otras dictaduras fascistas (Molinero, 2006). Sin embargo, no podemos ignorar el valor cualitativo que tenía para la construcción simbólica del régimen y de la imagen de las mujeres.

Entre las diferentes organizaciones femeninas, dependiendo de la naturaleza de la celebración y el poder que detentaran, cada una ocupaba el sitio que le correspondiese por su origen político, social o religioso. En 1937, en plena Guerra Civil y dentro de la procesión del Corpus Christi organizada en la localidad granadina de Fuente Vaqueros, las mujeres de la Sección Femenina se encontraban relegadas a una posición secundaria por otras organizaciones femeninas de carácter católico como las Hijas de María, pese a tener un mayor peso dentro del Estado que estas últimas, aunque este fuera aún menor del que adquirirían en los años siguientes (Gallego Méndez, 1983: 47-79):

"A las ocho de la mañana, organizándose el acto, abriendo marcha la Legión de Flechas con tambores. Iban a continuación las Hijas de María, agrupación de madres cristianas con sus respectivas insignias, Sección Femenina de F E. 
T., niños y niñas de las escuelas nacionales con sus profesores, coros de ángeles primorosamente ataviados, Cruz alzada, ciriales, etc." ${ }^{5}$

Del mismo modo, su participación estaba muchas veces supeditada a una serie de normativas que organizaban y determinaban qué posiciones, acciones o símbolos debían guiar cada paso. Esto era imprescindible para generar el sentido con el que se quería dotar a las festividades y para ofrecer la representación ideal de la organización y sus miembros. Elementos como la vestimenta estaban completamente reglados para ofrecer ese sentido de homogeneidad que quería mostrarse (Blasco Herranz, 1997; Pelka, 2014; Vincent, 2017). Para la celebración del "Día de la Victoria", el 1 de abril de 1940, las militantes o adheridas a la Sección Femenina granadina debían estar "perfectamente uniformadas" con el típico uniforme compuesto por boina roja, camisa azul y falda negra, o, en el caso de que algunas de las invitadas careciesen de estos, podían concurrir vestidas de color oscuro pero identificándose con el emblema de la organización en todo momento. A través de la ropa manifestaban su adhesión al régimen y a la organización femenina, despertando al mismo tiempo un compromiso que las llevaba a ir más allá de las palabras a una representación corporal de su posición política (Richmond, 2004: 104).

Durante las festividades cada acción también procuraba estar minuciosamente ordenada. A todas se hacían partícipes de las festividades y se las organizaba previamente para que la escenificación fuese lo más adecuada posible. Por medio de la prensa o en los locales de la Sección Femenina se les exponía cómo debían de proceder a lo largo de la jornada y las consecuencias punitivas que podía acarrear el que no cumpliesen con las órdenes:

«Normas que seguirán todas las afiliadas a esta Sección femenina de Falange Española Tradicionalista de las J. O. N. S. el día 29 de octubre, fiesta de los Caídos [...]:

2. Cada afiliada irá al lugar designado para su distrito [especificado en el primer punto], uniformada y con boina negra reglamentaria o a falta de ella con velo, a las diez en punto.

3. Cada jefe de distrito pasará lista de todas las afiliadas y las que falten serán sancionadas.

4. A las diez y media irán todas juntas a la Catedral.

5. A la salida de la Catedral marcharán al lugar donde se levantará la Cruz de los Caídos y presenciarán el desfile.

El incumplimiento de cualquiera de estas órdenes será sancionado. -La Delegada local». ${ }^{6}$

\footnotetext{
${ }^{5}$ Ideal, 3-6-1937, 6.

${ }^{6}$ Ideal, 29-10-1937, 4.
} 
Como puede observarse en este bando, las falangistas de todas las edades debían estar horas antes para proceder al control de asistencia. La no asistencia podía ser reflejada en sus expedientes como una mancha negra que mancillaría sus futuras trayectorias en la Sección Femenina o si pretendían acceder a algunos puestos dentro de las instituciones públicas. Consecuentemente, la participación no era libre y entusiasta, como podría parecer en la propaganda o en otras fuentes de la época. ${ }^{7}$ Sin duda, muchas mujeres participaron de buena gana en estas festividades que representaban sus afinidades políticas o religiosas, pero otras, cuya presencia en este tipo de celebraciones podía resultar una obligación, eran movidas a participar bajo mecanismos de coerción cuyas consecuencias podían ser percibidas como fatales.

Viendo estas fuentes puede apreciarse que este tipo de celebraciones, al menos para Falange, poseían una gran importancia. Dentro del calendario existían algunas fechas donde la participación femenina se alentaba y en las que muchas participaban en una serie de rituales dirigidos especialmente para ellas. Los días de la muerte de Santa Teresa, patrona de la Sección Femenina, y de José Antonio Primo de Rivera, líder espiritual de estas, junto con otras festividades como la de San Isidro Labrador, patrón de la Hermandad de la Ciudad y el Campo de la Sección Femenina, configuraban un pequeño "calendario franquista de la mujer" que brindaban verdaderos espacios de socialización política para estas mujeres. Espacios donde, dentro de las condiciones impuestas, ellas mostrarían su mayor agencia a la vez que ayudarían a consolidar y establecer los límites de algunas de las feminidades hegemónicas del franquismo.

\section{Hijas de Teresa}

A partir del 15 de octubre de 1938 esta fecha se estableció como el día de la patrona de la Sección Femenina de Falange con motivo del fallecimiento de Teresa de Jesús, la cual fue tomada como modelo por ser "una de las mujeres que más gloria ha dado a España". ${ }^{8}$ Teresa de Ávila (1515-1582), la "Santa de la Raza", cuya experiencia vital fue uno de los primeros grandes testimonios autobiográficos femeninos de la modernidad (Van Dülmen, 2016: 32-35), se convirtió durante el Barroco en todo un ejemplo de feminidad, patriotismo y catolicismo para los españoles (Weber, 2003; Morcillo Gómez, 2015: 71). Siglos más tarde, esta fue instrumentalizada por las culturas políticas franquistas como la imagen ideal que reunía todos los caracteres de la mujer pues, por su "feminismo cristiano", era considerada como un gran ejemplo: "apacible, tranqui-

${ }^{7}$ Ideal, 31-3-1940, 11; Ideal, 10-4-1940, 5.

${ }^{8}$ Archivo Nueva Andadura (ANA): "Circular de 15 de octubre de 1938", 1:2, 1938. 
la y serena y llena de dulzura, en esa dulzura tan española y tan femenina de la mujer de España"9 y, más concretamente, de la mujer de la Sección Femenina (Di Febo, 1988).

Junto con otras mujeres de la historia de España como Isabel de Castilla, ${ }^{10}$ su figura no solo funcionó como un modelo de feminidad sino también como un símbolo para articular otros aspectos rituales y discursivos fundamentales para las organizaciones femeninas del franquismo (Ofer, 2005). A través de la conmemoración de la muerte de Teresa de Ávila se representaba y reafirmaba la relación de subordinación de las mujeres a la fe católica y al falangismo, se realizaba el rito iniciativo de las "flechas azules" dentro de la Sección Femenina adulta y se hacía balance de la labor realizada a nivel local y provincial por toda España. Esta festividad era un espacio anual para invocar los cambios acaecidos a nivel individual y colectivo en la mujer falangista, por lo que poseyó una gran importancia durante los años de la posguerra, especialmente en aquellos donde el falangismo tuvo más fuerza (Richmond, 2004: 88-89).

En 1941, la jornada empezó en Granada a las nueve y media de la mañana con una misa de comunión general en el convento de las Carmelitas Descalzas, orden que fundó Teresa de Jesús, donde comulgaron la totalidad de las afiliadas a la Sección Femenina. Como bien había hecho saberse desde las delegaciones, "todas las camaradas sin excepción" debían esta citadas. ${ }^{11}$ En aquella ceremonia recibieron la eucaristía como aceptación del cuerpo de Cristo y, en virtud de ello, como reafirmación de su fe católica ante sus compañeras y los representantes de la Iglesia. ${ }^{12} \mathrm{Al}$ mismo tiempo, esta reafirmación valía para afianzar su sujeción al régimen franquista puesto que el catolicismo era uno de sus grandes pilares. El hecho de que todas ellas participasen obligatoriamente en la misa era sintomático del control que se quería ejercer para que siguiesen participando en la organización y para que el ritual tuviese una mayor fuerza comunicativa al movilizar a un mayor número de personas.

A continuación, a las once de la mañana, se realizó un acto de marcado carácter simbólico para las muchachas del Frente de Juventudes en el que se escenificaba su pase de "flechas azules", aquellas afiliadas menores de dieci-

\footnotetext{
${ }^{9}$ Patria, 15-10-1941, 3.

${ }^{10}$ Sobre el estudio de personajes históricos como modelos de feminidad: Di Febo (1988), Ofer (2005) y Maza Zorrilla (2014).

${ }^{11}$ ANA: "Circular 137: Instrucciones para la celebración del día de Santa Teresa, patrona de nuestras secciones femeninas", 1:2, 1939.

${ }^{12}$ Patria, 15-10-1941, 1.
} 
siete años y "esperanza de la Falange", ${ }^{13}$ a la Sección Femenina adulta. Ese mismo año pasaron 149 flechas del Frente de Juventudes, mientras que solo dos años más tarde, en 1943, las cifras de la capital granadina descendieron de tal modo que únicamente 20 serían las que pasasen a formar parte de la organización desde abajo. Esto nos habla de las dificultades para continuar captando nuevas granadinas que engrosaran sus filas debido a las carencias humanas y materiales y a la pérdida de peso de la Sección Femenina frente a otras organizaciones femeninas de signo católico (Jiménez Aguilar, 2018: 188-191). Con este ritual lo que se buscaba representar era el paso de las jóvenes a una nueva etapa de madurez al convertirse en "mujeres". Esto conllevaba tanto el reconocimiento de una serie de transformaciones individuales como la aceptación de nuevas responsabilidades colectivas que tendrían dentro de la Sección Femenina en adelante. Para simbolizarlo en aquel acto, primero habló la responsable de la Sección Femenina del Frente de Juventudes para despedirse de ellas, se intercambiaron los "guiones" y se cantó el Cara al sol. Habían escenificado en ese preciso momento su comunión con el régimen según Franco había mostrado en la concentración de Medina del Campo en 1939.14

Ya por la tarde, en el cuartel de Frente de Juventudes se realizaron actuaciones corales donde la regiduría de Coros y Danzas interpretó canciones tradicionales de la provincia. En estos espectáculos musicales se reforzaban muchos de los discursos nacionales, regionales y de género que la Sección Femenina se encargó de reproducir (Enders, 1992; Casero, 2000; Bergés, 2012). Para concluir la jornada, la delegada provincial, María Encarnación Marzal, llevó a cabo el balance anual de la Sección Femenina en la provincia y de todos aquellos retos que debían afrontarse en el futuro. ${ }^{15}$ Seguidamente, la delegada leyó el nombre de aquellas camaradas condecoradas con las "Y" de oro, plata y roja, las cuales representaban el emblema de la reina Isabel la Católica y se les entregaban a aquellas mujeres premiadas por su labor a nivel nacional o a las que habían muerto en acto de servicio (Ofer, 2009: 58-67; Biggane, 2013). La sesión terminó, como no podía ser de otra forma, con la interpretación del himno de Falange. A lo largo de esta última parte se las hacía conocedoras de los logros y desafíos que afrontaba la organización, por lo que no eran ajenas a la realidad que les rodeaba. De la buena organización de la Sección Femenina a nivel individual, local y nacional dependería en parte la imagen y la continuidad del régi-

${ }^{13}$ Ideal, 16-10-1941, 6.

${ }^{14}$ ANA: "Circular 137: Instrucciones para la celebración del día de Santa Teresa, patrona de nuestras secciones femeninas", 1:2, 1939.

${ }^{15}$ Ideal, 16-10-1941, 6; Patria, 15-10-1941, 1. 
men, por lo que la existencia de instrumentos como la entrega de los premios "Y", esta festividad o los Consejos Nacionales de la Sección Femenina que se celebraban anualmente, nos hablan de un control de la actividad que se realizaba y de la existencia de un proyecto político femenino, aunque este fuese truncado muchas veces por las circunstancias.

Durante esta festividad otros eventos podían tener lugar, como demostraciones gimnásticas, juegos populares o actuaciones teatrales realizadas por los distintos servicios de la Sección Femenina, ${ }^{16}$ exhibiéndose así los resultados de la labor de las delegaciones y regidurías orientadas a la educación y a la formación ideológica de las mujeres. De igual modo, se intentaba que en gran parte de los pueblos que contaban con Sección Femenina se celebrara esta festividad en honor a Santa Teresa, ${ }^{17}$ aunando los rituales de carácter religioso y falangista, como misas de comunión, interpretaciones de canciones o la lectura de algún discurso de Pilar Primo de Rivera con una clara significación de género, como el que se leyó en 1939:18

"Tenéis que enseñar por todas las tierras de España, el ansia de nuestra Revolución

Tenéis que andar por todos los caminos y llevar a todos los espíritus este modo de ser que nos enseñó José Antonio

Pero de una manera callada, sin exhibiciones y sin discursos, porque esas cosas no son propias de mujeres. Sino sencillamente, como lo hizo Santa Teresa

Con espíritu misionero y Nacionalsindicalista, iréis llevando por todas las tierras que conquistan los soldados de Franco, el calor de la hermandad de nuestra doctrina,

Alegremente llevaréis el pan a los pueblos recién conquistados. Y como ella no os canséis aunque la dificultad se ponga de vuestro camino, que es esa la única manera de hacer grandes cosas.

Y ahora Teresa de Jesús protege a las Secciones Femeninas para que no den paso en falso y para que obren siempre conforme a la ley de Dios y a las ordenes Nacional Sindicalistas que recibimos de Franco"19.

Bajo el amparo que proporcionaba un símbolo como el de Santa Teresa las mujeres de la Sección Femenina ritualizaron y festejaron durante muchos años aquellos elementos que engranaban su buen funcionamiento: la adhesión al falangismo, el "vivir cristianamente", ${ }^{20}$ la movilización de nuevas mujeres y

${ }^{16}$ ABC, 17-10-1939, 11; La Prensa, 16-10-1944, 2.

17 ANA: "Circular 137: Instrucciones para la celebración del día de Santa Teresa, patrona de nuestras secciones femeninas", 1:2, 1939.

${ }^{18}$ Ideal, 18-10-1938, 6.

${ }^{19}$ Patria, 15-10-1939, 4.

${ }^{20}$ Hoja Oficial del Lunes, 16-10-1939, 3. 
el control de la organización y sus mujeres. Todo esto permitía fundar un espacio anual donde encauzar y reforzar la labor realizada por la Sección Femenina y la imagen de esta, pues no podía concebirse por parte de la organización que aquellas mujeres que dedicaban la mayor parte de su vida al régimen dieran un "paso en falso" en su tarea de controlar a las mujeres.

\section{Plañideras del "Ausente"}

El 20 de noviembre se convirtió en la otra gran fecha del calendario femenino franquista. Aquel día se conmemoraba en toda España la muerte de José Antonio Primo de Rivera, la cual sería una de las manifestaciones más características de "culto a los mártires" que hubo durante el periodo de entreguerras (Payne, 1997: 372-373). El culto a los caídos fue un elemento fundamental de la "Cultura de la Victoria", siendo la imagen de la muerte por la patria, honrada a través del ritual funerario y del luto, un eficaz instrumento de legitimación para los vencedores y exclusión para los vencidos. Se crearon a raíz de ello nuevas festividades como el "Día de los Caídos" (29 de octubre) o la "Fiesta del Estudiante Caído" (9 de febrero), se erigieron monumentos funerarios como las cruces de los caídos y se modificó el cortejo fúnebre y el duelo de acuerdo con las culturas políticas franquistas. ${ }^{21} \mathrm{Y}$ entre todos estos rituales, el funeral de José Antonio Primo de Rivera en 1939 se convirtió en el más claro ejemplo al movilizar a la sociedad española y a los medios de comunicación en una larga marcha fúnebre que fue desde Alicante hasta San Lorenzo de El Escorial durante dos semanas (Box, 2011: 160-177; Thomàs, 2017: 391-422).

La importancia para la Sección Femenina de la figura de José Antonio y su "Día del Dolor", más allá de la importancia que este culto tenía para el "Nuevo Estado", respondía al valor que poseía su figura y pensamiento dentro del sistema de creencias del franquismo y de la organización. Muestra de ello era el hecho de que no faltaba un ejemplar de sus obras completas en cada biblioteca de la Sección Femenina ${ }^{22}$ o que todo espacio simbólico que guardara alguna relación con él estuviese convertido en un museo, como la cárcel alicantina donde murió. ${ }^{23}$ Desde su muerte y con gran interés por su hermana Pilar Primo de Rivera, Delegada Nacional de la Sección Femenina, la organización se echaría la carga de ser "vestales de su culto", como apuntó en el II Consejo Nacional de la Sección Femenina Raimundo Fernández Cuesta

${ }^{21}$ Véase, Vincent (1999: 89-94); Ledesma y Rodrigo (2006); Box (2010: 119-196); Hernández Burgos (2011: 127-156); Del Arco Blanco (2013).

${ }^{22}$ ANA, 4, doc. 1-2-3-4.

${ }^{23}$ Hoja Oficial del Lunes, 20-11-1939, 1. 
(Baisotti, 2015: 185), convirtiéndose así en las más acérrimas defensoras de su figura bajo la dictadura.

Cualquier 20 de noviembre en la Granada de los años cuarenta se organizaba por la mañana una misa en su honor en la Iglesia del Sagrario, situada junto a la Catedral y la Capilla Real, lugar este último donde se encontraban las tumbas de los Reyes Católicos y sus herederos. Una ceremonia religiosa a la que también debían asistir obligatoriamente todas las afiliadas de la Sección Femenina ${ }^{24}$ y en la que las más altas jerarquías de esta ocupaban un lugar destacado entre los escaños del templo. Luego, ya en la calle, se realizaba la colocación de las coronas de flores bajo el rótulo del "fundador" que había sido inscrito en su homenaje en la pared principal del templo o en la cruz de los caídos. ${ }^{25}$ Todo ello amenizado por la banda de música municipal y los gritos de “iPresente!” Pese a que las falangistas no participaran directamente en el ritual, debían hacer en todo momento acto de presencia, uniformadas o vestidas de luto, calladas y compungidas entre los allí reunidos, mostrando la imagen normativa del duelo. ${ }^{26}$

A lo largo de la tarde y entre los diferentes actos que se llevaban a cabo en la ciudad, las afiliadas debían reunirse en el Cuartel del Frente de Juventudes para rezar un rosario por "sufragio de su alma" frente a las jerarquías del partido. ${ }^{27}$ Inmediatamente después de las plegarias se procedía a la lectura de su testamento por parte del jefe provincial de Falange o del texto escrito por el propio José Antonio Primo de Rivera, "Mientras España duerme la siesta". ${ }^{28}$ En todo momento las mujeres de la Sección Femenina debían seguir encarnando el luto por José Antonio, un duelo que se materializaba en una participación silenciosa en todos los rituales, y en la oración por el alma del líder falangista en el ámbito privado. Sin embargo, y esto es aquí lo importante, siempre quedaba constancia de ella en la prensa y la propaganda oficial significando así que el verdadero lugar de las mujeres en este tipo de celebraciones era el de legitimar qué vidas merecían o no ser lloradas (Butler, 2017b).

Las mujeres de la Sección Femenina cumplían con su luto público una función ritual esencial para la construcción de la comunidad política nacional (Langarita Gracia, 2016). Por un lado, dotaban de valor la vida de José Antonio primo de Rivera y todas las connotaciones que esta comportaba: el nacionalsin-

${ }^{24}$ ANA: "Circular 185: Instrucciones para la celebración del 20-N", 1:2, 1941.

${ }^{25}$ Hoja Oficial del Lunes, 20-11-1939, 4.

${ }^{26}$ Patria, 21-11-1943, 7.

${ }^{27}$ La Prensa, 20-11-1944, 1; La Prensa, 21-11-1949, 1.

${ }^{28}$ ANA, "Circular 185: Instrucciones para la celebración del 20-N", 1:2, 1941; ANA, "Circular 197", 1:2, 1942. 
dicalismo como ideología, la concepción palingenésica de España, la legitimidad del Golpe de Estado del 36 o la imagen de los mártires como principales sujetos políticos, entre otros. De este modo, a través de su posición en el ritual expresaban qué tipos de vidas merecían vivir y, por tanto, cuáles eran los caracteres de la cultura franquista. Por otro lado, delimitaban cuál era la posición de las mujeres dentro de la sociedad, que para el caso era la de sustentar el falangismo desde una posición apartada y silenciosa. Con lo cual se significaban cuál era la agencia de las mujeres en los espacios públicos y privado, organizados todos ellos en torno a que sus vidas, se encontraran siempre en una posición supeditada a la figura del hombre, que en este caso simbolizaba el propio José Antonio.

Aunque el ritual fue transformándose con el tiempo, este sirvió para unir a las mujeres en torno a su líder, una unión que, a pesar del peso católico imperante en el ritual, tenía como objetivo principal la reivindicación ideológica del gran representante del fascismo español junto con Franco. Esto es algo que no podemos ignorar si queremos entender la paulatina pérdida de poder del falangismo frente al nacionalcatolicismo en estos rituales, las transformaciones culturales que esto conllevó y los momentos de revitalización del proyecto falangista tras los sucesos de 1941 y 1942, donde las mujeres de la Sección Femenina también participaron.

\section{Labradoras de San Isidro}

Lejos de las ciudades, a lo largo y ancho del mundo rural, la Regiduría de la Hermandad de la Ciudad y el Campo comenzó a publicitar en 1941 la celebración cada 15 de mayo de su patrón, San Isidro Labrador. Como ha expuesto Sescún Marías, San Isidro se erigió al igual que Santa Teresa como un referente religioso para la sociedad española al ser personificado como uno de sus primeros mártires y como portador de la "raza". Mediante su figura se empezó a organizar una festividad con un doble propósito religioso y doctrinario que servía gracias a distintos rituales y actividades para reproducir entre las gentes del campo, ideas y valores morales, familiares y productivos que entroncaban directamente con las culturas políticas del franquismo (Marías Cadenas, 2011: 212-213; Alares López, 2011: 138-145).

La festividad de San Isidro poseía mucho antes de la guerra civil representación en numerosos lugares de toda España, siendo las fiestas patronales de Madrid las más conocidas. En la provincia de Granada se celebraba en algunas localidades como Lanjarón, Zujaira, una pedanía perteneciente a Pinos Puente, o Puntalón, anejo de Motril, teniendo realmente un mayor peso en 
otras provincias andaluzas como Córdoba o Huelva. No obstante, la Sección Femenina tuvo durante los primeros años de posguerra la orden de empezar a instaurar esta festividad a nivel nacional en algunas ciudades y, sobre todo, en los nuevos pueblos de orientación agraria que fundó el Instituto Nacional de Colonización por todo el país (Marías Cadenas, 2011: 213).

Para las instituciones franquistas esta celebración tenía una gran importancia para cohesionar y dirigir a muchos de los organismos y gentes del agro, por lo que pasó de tener un carácter meramente religioso a poseer connotaciones políticas. ${ }^{29}$ Por el día, a las once en punto, todos los cargos de la Sección Femenina y de la regiduría de la Hermandad, junto a un representante provincial del partido en Granada, acudieron a la misa oficiada en la iglesia parroquial de San Ildefonso. Tras la ceremonia religiosa, el párroco bendijo los frutos típicos de la provincia que, seguidamente, las mujeres de falange llevaron ataviadas con trajes regionales o de servicio, mientras que las muchachas de la Sección Femenina del Frente de Juventudes hacían ofrendas florales, ${ }^{30}$ yendo de dos en dos, arrodillándose y entregando las ofrendas ante los pies de la imagen del santo. ${ }^{31}$ Con ello significaban individualmente su fe y la solicitud de amparo religioso tanto para la cosecha del pueblo como para la labor que desarrollaba la Hermandad y las otras regidurías de la Sección Femenina orientadas al campo. Esto no solo era una muestra de la orientación católica de las prácticas festivas, sino también de que paulatinamente el nacionalcatolicismo iba acaparando un mayor peso en la cultura del régimen y en la vida de los españoles.

Ya por la noche se organizaba una emisión de radio en la que se hablaba de la figura de San Isidro Labrador y que acostumbraba a usarse como pretexto para resaltar la labor de la Sección Femenina y la Hermandad de la Ciudad y el Campo en la provincia. ${ }^{32}$ Aquella fecha servía como escaparate para mostrar las actividades que se estaban desplegando en los pueblos por medio de la Divulgación y Asistencia Sanitario Social o las Cátedras Ambulantes, mientras ellas eran protagonistas en muchos de sus rituales más significativos. Después, la radio o la prensa se encargarían de subrayar que ellas estaban allí, trabajando silenciosamente para levantar la "Nueva España".

En otros lugares, a parte de las conocidas verbenas, se realizaban procesiones y cultos al santo, exposiciones ganaderas y florales, bailes regionales, inter-

${ }^{29}$ Así puede apreciarse en las celebraciones que se daban en la provincia, incluso después de concluir la guerra. Véase, Hoja Oficial del Lunes, 15-5-1939, 2.

${ }^{30}$ Patria, 16-5-1945, 4; ABC, 14-5-1943, 10.

${ }^{31}$ ABC, 16-5-1944, 10.

${ }^{32}$ Patria, 16-5-1943, 6. 
pretaciones de los Coros y Danzas, conciertos, concursos y entregas de alimentos a los más necesitados. ${ }^{33}$ En general, durante esta festividad se desplegaba todo tipo de actividades y eventos que servían para acercar al pueblo al régimen, recogiendo elementos de la religiosidad popular, elementos comunes del mundo rural y del folklore que la Iglesia, las instituciones locales y la Sección Femenina sabían adaptar para tal fin (Marías Cadenas, 2011: 218-220). A nivel organizativo y práctico las afiliadas tendrían aquí un rol destacado al ser representadas como "misioneras del falangismo" en el campo español, por lo que esta celebración suponía una prueba más del importante papel que tenían las mujeres al llevar a la vida cotidiana del campo los ideales del franquismo.

\section{Conclusiones}

Desde hace ya muchos años la historiografía ha demostrado cómo durante el primer franquismo las mujeres participaron y se resistieron a la nueva realidad política de la dictadura, la cual se impuso en gran medida por medio de la fuerza y procuró la existencia de estas bajo unas mayores condiciones de desigualdad. Por ello, no podemos continuar reduciéndolas a meros "ángeles del hogar" y sí debemos reconocer la participación de las mujeres dentro de las esferas pública y privada, pese a sus limitaciones, y la importancia que esta tenía para el régimen franquista y para la (re)producción del discurso de género de la Sección Femenina. También tenemos que admitir la agencia que muchas mujeres tuvieron a través de su participación en la Sección Femenina para no perder de vista la complejidad de los procesos que se dieron antes de la Guerra Civil y después de esta, en medio de una transición bélica y violenta entre un régimen democrático considerablemente inclinado a la ampliación de los derechos de las mujeres y otro dictatorial abiertamente antifeminista, pues muchos de los procesos políticos, jurídicos, económicos y culturales que en diferente grado de orientación igualitaria se habían dado fueron truncados durante estos años por distintas dinámicas políticas antifeministas, capitalistas o religiosas. Al observar la agencia de las mujeres podemos ver la variedad de discursos y prácticas que determinaron la posición de la mujer durante la dictadura y la complejidad de los procesos de pérdida de derechos y de transformación social.

Para efectuar nuestro análisis nos hemos acercado a aquellas celebraciones franquistas en las que las mujeres de la Sección Femenina participaron de manera más destacada. Las celebraciones, al igual que otros espacios rituales públicos, sirvieron para representar y ritualizar símbolos, discursos y actitudes que

${ }^{33}$ ABC, 16-5-1944, 20; ABC, 16-5-1947, 10; La Prensa, 15-5-1950, 5. 
estructuraban la realidad política. Consecuentemente, estos han de ser considerados tanto espacios de fascistización, nacionalización, catolización o generización, como de subversión política, económica y cultural, aunque estos últimos no hayan sido objeto de este estudio. Para el caso de las mujeres de la Sección Femenina, las celebraciones servían tanto para la representación de su posición privilegiada frente a otras mujeres como para la que les correspondía dentro del régimen, por lo que trazaban muchos de los límites de su identidad política y de género.

Todas estas fiestas que hemos examinado tenían diversas finalidades políticas. Los rituales que se realizaban en estas servían para construir en la esfera pública significados, vínculos y experiencias que permitían legitimar algunos cambios políticos o el que todo siguiera igual dentro de la organización y fuera de esta. También, durante los días de Santa Teresa, San Isidro o José Antonio Primo de Rivera, las mujeres de la Sección Femenina y otras españolas se vieron insertas en diferentes procesos de producción de sentido y de representación de determinados modelos hegemónicos de feminidad. De la misma forma, estas participaron en su normalización y legitimación para el resto de la sociedad que era partícipe por diferentes vías en estos rituales. De este modo, pese a que el franquismo fue arrinconando a las mujeres en la esfera pública, muchas siguieron participando en ella, aunque de forma marginal y cumpliendo siempre un fin fundamental: simbolizar su subyugación a él como españolas, falangistas, católicas y, sobre todo, mujeres. Así las celebraciones franquistas sirvieron como un campo de batalla más por el que desfilaron las mujeres falangistas profundizando, por otros medios, la política antifeminista del franquismo.

\section{Bibliografía}

ALARES LÓPEZ, Gustavo (2011). Ruralismo, fascismo y regeneración. Italia y España en perspectiva comparada. Ayer, 83:3, 127-147.

ANTUNA GANCEDO, Enrique A. (2016). La intervención del primer franquismo sobre la fiesta popular: una aproximación a través del caso asturiano. Hispania Nova, 14, 192-212. <https://e-revistas.uc3m.es/index.php/HISPNOV/article/view/ 2971/1675>

BAISOTTI, Pablo A. (2015). Ausente-Presente: las dos caras de José Antonio (19361938). Memoria y Civilización, 18, 163-189. <http://dx.doi.org/10.15581/001.18.163 $-189>$

BARRACHINA, Marie Aline (1991). Ideal de la Mujer Falangista. Ideal Falangista de la Mujer. Las mujeres en la Guerra Civil Española, III Jornadas de Estudios Monográficos. Salamanca, 1989 (211-217). Madrid: Instituto de la Mujer y Ministerio de Trabajo e Inmigración. 
BERGÉS, Karine (2012). La nacionalización del cuerpo femenino al servicio de la construcción de la identidad nacional en las culturas políticas falangistas y franquistas. Mélanges de la Casa de Velázquez, 42:2, 91-103. <http://journals.openedition. org/mcv/4578>

BIGGANE, Julia (2013). The Rewards of Female Fascism in Franco's New Sate: The Recompensas Y of the Sección Femenina de la Falange, 1939-1945. Bulletin of Spanish Studies, 90:8, 1313-1337. <https://doi.org/10.1080/14753820.2013.847159>

BLASCO HERRANZ, Inmaculada (1997). Moda e Imágenes Femeninas durante el Primer Franquismo: entre la Moralidad Católica y las Nuevas Identidades de Mujer. Utopía y Praxis Latinoamericana, 2:2, 83-93. <http://produccioncientificaluz.org/ index.php/utopia/article/view/17704/17686>

BLASCO HERRANZ, Inmaculada (2005). "Sección Femenina" y "Acción Católica": la movilización de las mujeres durante el Franquismo. Gerónimo de Uztariz, 21, 55-66. <file:///C:/Documents\%20and\%20Settings/Usuario/Mis\%20documentos/Downloads /Dialnet-SeccionFemeninaYAccionCatolica-2173582\%20(2).pdf>

BOX, Zira (2007). El calendario festivo franquista: tensiones y equilibrios en la configuración inicial de la identidad nacional del régimen. En Javier MORENO LUZÓN (coord.). Construir España: nacionalismo español y procesos de nacionalización (263288). Madrid: Centro de Estudios Políticos y Constitucionales.

BOX, Zira (2010). España, año cero. La construcción simbólica del franquismo. Madrid: Alianza Editorial.

BUTLER, Judith (2010). Performative Agency. Journal of Cultural Economy, 3:2, 147 161. <https://doi.org/10.1080/17530350.2010.494117>

BUTLER, Judith (2015). El género en disputa. El feminismo y la subversión de la identidad. Barcelona: Paidós [1990].

BUTLER, Judith (2017a). Cuerpos aliados y lucha política. Hacia una teoría preformativa de la asamblea. Barcelona: Paidós [2015].

BUTLER, Judith (2017b). Marcos de guerra. Las vidas lloradas. Barcelona: Paidós [2009].

CASERO, Estrella (2000). La España que bailó con Franco: Coros y Danzas de la Sección Femenina. Madrid: Nuevas Estructuras.

CAYUELA SÁNCHEZ, Salvador (2014). Por la grandeza de la patria. La biopolítica en la España de Franco. Madrid: Fondo de Cultura Económica.

CENARRO, Ángela (2003). Los días de la "Nueva España": entre la "revolución nacional" y el peso de la tradición. Ayer, 51, 117-134.

CENARRO, Ángela (2006). Movilización femenina para la guerra total (1936-1939). Un ejercicio comparativo, Historia y Política, 16, 159-182. <http://www.cepc.gob.es/ publicaciones/revistas/revistaselectronicas? IDR=9\&IDN=645\&IDA=26808>

CENARRO, Ángela (2011). Trabajo, maternidad y feminidad en las mujeres del fascismo español. En Ana M. AGUADO; Teresa María ORTEGA LÓPEZ (eds.). Feminismos y antifeminismos. Culturas políticas e identidades de género en la España del siglo XX (229-252). Valencia y Granada: Publicacions de la Universitat de València y Editorial Universidad de Granada. 
CENARRO, Ángela (2017). La Falange es un modo de ser (mujer): discursos e identidades de género en las publicaciones de la Sección Femenina (1938-1945), Historia y Política, 37, 91-120. <https://doi.org/10.18042/hp.37.04>

COBO ROMERO, Francisco; DEL ARCO BLANCO, Miguel Ángel; ORTEGA LÓPEZ, Teresa María (2011). The Stability and Consolidation of the Francoist Regime. The Case of Eastern Andalusia, 1936-1950. Contemporary European History, 20:1, 37-59. <https://doi.org/10.1017/S0960777310000366>

CORNER, Paul (2013). Habermas, Fascism, and the Public Sphere. En Michael KIM; Michael SCHOENHALS; Yong-Woo KIM (eds.). Mass Dictatorship and Modernity. Mass Dictatorship in the 20th Century (101-116). Londres: Palgrave Macmillan.

DAVIS, Belinda (1996). Reconsidering Habermas, Gender, and the Public Sphere: The Case of Wilhelmine Germany. En Geoff ELEY (ed.). Society, Culture and State in Germany, 1870-1930 (397-426). Ann Arbor: University of Michigan Press.

DEL ARCO BLANCO, Miguel Ángel (2009). El secreto del consenso en el régimen franquista: cultura de la victoria, represión y hambre. Ayer, 76, 245-268.

DEL ARCO BLANCO, Miguel Ángel (2013). Las cruces de los caídos: Instrumento nacionalizador en la "Cultura de la Victoria". En Miguel Ángel DEL ARCO BLANCO et al. (eds.). No solo miedo. Actitudes políticas y opinión popular bajo la dictadura franquista (1936-1977) (65-83). Granada: Comares.

DI FEBO, Giuliana (1979). Resistencia y movimiento de mujeres en España 1936-1976. Barcelona: Icaria.

DI FEBO, Giuliana (1988). La santa de la raza. Un culto barroco en la España franquista. Barcelona: Icaria.

DI FEBO, Giuliana (2012). Ritos de guerra y de victoria en la España franquista. Valencia: Publicacions de la Universitat de València.

ELEY, Geoff (2002). Politics, Culture and the Public Sphere. Positions, 10:1, 219-236. <https://muse.jhu.edu/article/27999>

ENDERS, Victoria L. (1992). Nationalism and Feminism: The Seccion Femenina of the Falange. History of European Ideas, 15:4-6, 673-680. <https://doi.org/10.1016/ 0191-6599(92)90077-P>

ENDERS, Victoria L. (1999). Problematic Portraits: The Ambiguous Historical Role of the Sección Femenina of the Falange. En Victoria L. ENDERS; Pamela B. RADCLIFF (eds.). Constructing Spanish Womanhood: Female Identity In Modern Spain (375-397). Albany: Sate University of New York Press.

FRASER, Nancy (1990). Rethinking the Public Sphere: A Contribution to the Critique of Actually Existing Democracy. Social Text, 25/26, 56-80. <https://www.jstor.org/sta ble/466240>

FRASER, Nancy (2015). Fortunas del feminismo. Del capitalismo gestionado por el Estado a la crisis neoliberal. Madrid: Traficantes de Sueños.

GALLEGO MÉNDEZ, María Teresa (1983). Mujer, falange y franquismo. Madrid: Taurus.

GENTILE, Emilio (1990). Il culto del littorio. La sacralizzazione della politica nell'Italia fascista. Roma: Laterza. 
HABERMAS, Jürgen (1989). The Structural Transformation of Public Sphere. An inquiry into a Category of Bourgeois Society. Cambridge: MIT.

HERNÁNDEZ BURGOS, Claudio (2011). Granada Azul. La construcción de la "Cultura de la Victoria" en el primer franquismo. Granada: Comares.

HERNÁNDEZ BURGOS, Claudio (2016a). Los fascistas, lo público y la producción del espacio. En Francisco COBO ROMERO; Claudio HERNÁNDEZ BURGOS; Miguel Ángel DEL ARCO BLANCO (eds.). Fascismo y modernismo. Política y cultura en la Europa de entreguerras (1918-1945) (187-200). Granada: Comares.

HERNÁNDEZ BURGOS, Claudio (2016b). De la cultura de la guerra a la cultura de la victoria: los vencedores y al construcción de la dictadura franquista (19361951). Pasado y Memoria. Revista de Historia Contemporánea, 15, 123-148. <https:// doi.org/10.14198/PASADO2016.15.05>

IPIÑA BIDAURRAZAGA, Aritz (2014). "Bilbao ya es España". El modelo festivo franquista en Bilbao entre 1938 y 1940. Bidabarrieta: Revista de humanidades y ciencias sociales de Bilbao, 25, 153-164. <http://www.bidebarrieta.com/revista/25/\%E2\%80\% 9CBilbao-ya-es-Espana\%E2\%80\%9D.-El-modelo-festivo-franquista-en-Bilbaoentre-1938-y-1940>

JIMÉNEZ AGUILAR, Francisco (2017). Madrinas del franquismo. La Sección Femenina de Falange en Granada durante la Guerra Civil (1936-1939). Revista Historia Autónoma, 11, 199-218. <http://dx.doi.org/10.15366/rha2017.11.010>

JIMÉNEZ AGUILAR, Francisco (2018). Palancas de posguerra. La Sección Femenina y las políticas sociales en la Granada del primer franquismo (1939-1945). Revista del Centro de Estudios Históricos de Granada y su Reino, 30, 175-192. <http://www.cehgr.es/revista/index.php/cehgr/article/view/200/797986>

LANGARITA GRACIA, Estefanía (2016). Viudas eternas, vestales de la patria. El "luto nacional" femenino como agente cohesionador en la España franquista. Ayer, 103, 125-145.

LAVAIL, Christine (2008). De la creación de la Sección Femenina (1934) a la campaña electoral de 1936: modalidades de intervención de las mujeres falangistas en la esfera pública. Arenal. Revista de historia de las mujeres, 15:2, 345-370.

LEDESMA, José Luis y RODRIGO, Javier (2006). Caídos por España, mártires de la libertad. Víctimas y conmemoración de la Guerra Civil en la España posbélica. Ayer, 63, 233-255.

LOREY, Isabell (2017). Disputas sobre el sujeto. Consecuencias teóricas y políticas de un modelo de poder jurídico: Judith Butler. Avellaneda: La Cebra [1996].

MAHMOOD, Saba (2001). Feminist Theory, Embodiment, and the Docile Agent: Some Reflections on the Egyptian Islamic Revival. Cultural Anthropology, 16:2, 202-236. <https://www.jstor.org/stable/656537>

MARÍAS CADENAS, Sescún (2011). "Por España y por el campo". La Sección femenina en el medio rural oscense (1939-1977). Huesca: Instituto de Estudios Altoaragoneses.

MAZA ZORRILLA, Elena (2014). El mito de Isabel de Castilla como elemento de legitimidad política en el franquismo. Historia y Política, 31, 167-192.

<https://recyt.fecyt.es/index.php/Hyp/article/view/21542/2204l> 
MOLINERO, Carme (1998). Mujer, franquismo y fascismo. La clausura forzada en un "mundo pequeño". Historia Social, 30, 97-117. <https://www.jstor.org/stable/403 40520>

MOLINERO, Carme (2005). La captación de las masas. Política social y propaganda en el régimen franquista. Madrid: Cátedra.

MORAGA GARCÍA, María de los Ángeles (2008). Notas sobre la situación jurídica de la mujer durante el franquismo, Feminismo/s, 12, 228-252. <http://dx.doi.org/10.14198/fem.2008.12.09>

MORALES VILLENA, Amalia (2010). Género, mujeres, trabajo social y Sección Femenina. Historia de una profesión feminizada y con vocación feminista. Granada: Editorial Universidad de Granada [tesis doctoral].

MORANT I ARIÑO, Toni (2012). "Para influir en la vida del Estado futuro". Discurso -y práctica- falangista sobre el papel de la mujer y la feminidad, 1933-1945. Historia y Política, 27, 113-141. <https://recyt.fecyt.es/index.php/Hyp/article/view/41239>

MORCILlO GÓMEZ, Aurora (2015). En cuerpo y alma. Ser mujer en tiempos de Franco. Madrid: Siglo XXI.

MOSSE, George L. (2005). La nacionalización de las masas. Simbolismo político y movimientos de masas en Alemania desde las guerras napoleónicas al Tercer Reich. Madrid: Marcial Pons.

NÚÑEZ SEXIAS, Xosé M. (2006). ¡Fuera al invasor!: nacionalismos y movilización bélica durante la Guerra Civil española (1936-1939). Madrid: Marcial Pons.

OFER, Inbal (2005). Historical Models, Contemporary Identities: The Sección Femenina of the Spanish Falange and its Redefinition of the Term "Feminity". Journal of Contemporary History, 40:4, 663-674. <https://www.jstor.org/stable/30036353>

OFER, Inbal (2009). Señoritas in Blue. The making of a female political elite in Franco's Spain. Brighton: Sussex University Press.

ORTEGA LÓPEZ, Teresa María (2009). Conservadurismo, catolicismo y antifeminismo: la mujer en los discursos del autoritarismo y el fascismo (1914-1936). Ayer, 71, 53-83.

ORTEGA LÓPEZ, Teresa María (2010). "Hijas de Isabel”. Discurso, representaciones y simbolizaciones de la mujer y de lo femenino en la extrema derecha española del período de entreguerras. Feminismo/s, 16, 207-232. <http://dx.doi.org/10.14 198/fem.2010.16.10>

PAYNE, Stanley G. (1997). Franco y José Antonio. El extraño caso del fascismo español. Barcelona: Planeta.

PELKA, Anna (2014). Mujer e ideología en la posguerra española: feminidad, cuerpo y vestido. Historia Social, 79, 23-42. <https://www.jstor.org/stable/24330761>

PRADA RODRÍGUEZ, Julio (2008). "Mujeres contra la revolución": La movilización femenina conservadora durante la Segunda República española y la Guerra Civil. Amnis, 8. <https://amnis.revues.org/599\#ftn2>

RICHMOND, Kathleen (2004). Las mujeres en el fascismo español: La Sección Femenina de la Falange, 1934-1959. Madrid: Alianza Editorial. 
RINA SIMÓN, Cesar (2015). La construcción de los imaginarios franquistas y la "religiosidad popular", 1931-1945. Pasado y Memoria. Revista de Historia Contemporánea, 14, 179-194. <https://doi.org/10.14198/PASADO2015.14.07>

RODRÍGUEZ LÓPEZ, Sofía (2010). La Sección Femenina, la imagen del poder y el discurso de la diferencia. Feminismo/s, 16, 233-257.

<http://dx.doi.org/10.14198/fem.2010.16.11>

RUIZ FRANCO, Rosario (2007). ¿Eternas menores? Las mujeres en el franquismo. Madrid: Biblioteca Nueva.

SÁNCHEZ LÓPEZ, Rosario (1990). Mujer española, una sombra de destino en lo universal: trayectoria histórica de Sección Femenina de Falange (1934-1977). Murcia: Universidad de Murcia.

SAZ CAMPOS, Ismael (2004). Fascismo y franquismo. Valencia: Publicacions de la Universitat de València.

SAZ CAMPOS, Ismael (2010). Las culturas políticas del nacionalismo Español. En Manuel PÉREZ LEDESMA; María SIERRA (eds.). Culturas políticas: teoría e historia (313-329). Zaragoza: Institución Fernando el Católico.

SMITLEY, Megan (2009). The Feminine Public Sphere. Middle-Class Women in Civic Life in Scotland, c. 1870-1914. Manchester: Manchester University Press.

TAVERA GARCÍA, Susanna (2011). Las mujeres de la sección de la Falange: una afirmación entre el activismo político y la sumisión patriarcal 1934-1939. En Ana M. AGUADO; Teresa María ORTEGA LÓPEZ (eds.). Feminismos y antifeminismos. Culturas políticas e identidades de género en la España del siglo XX (207-228). Valencia y Granada: Publicacions de la Universitat de València y Editorial Universidad de Granada.

THOMÀS, Joan Maria (2017). José Antonio. Realidad y Mito. Barcelona: Debate.

VAN DÜLMEN, Richard (2016). El descubrimiento del individuo 1500-1800. Madrid: Siglo XXI.

VINCENT, Mary (1999). The Martyrs and the Saints: Masculinity and the Construction of the Francoist Crusade. History Workshop Journal, 47, 69-98. <https://doi.org/ 10.1093/hwj/1999.47.68>

VINCENT, Mary (2017). La semana santa en el nacionalcatolicismo: espacio urbano, arte e historia. El caso de Valladolid (1939-1949). Historia y Política, 38, 91-127. <http://revistas.ucm.es/index.php/HPOL/article/view/58642/52792>

WEBER, Alison (1993). Teresa d' Avila e la retorica della femminilità. Florencia: Le Littere. 